\author{
Alternating Gradient Synchrotron Department \\ BROOKHAVEN NATIONAL LABORATORY \\ Associated Universities, Inc. \\ Upton, New York 11973 \\ Experimental Planning and Support Division \\ Technical Note \\ June 1, 1987 \\ AGS/EP\&S/Tech. Note No. 125
}

\title{
BNLDAG VAX GMAIL
}

R. Imossi

\subsection{Electronic Mail Introduction}

Electronic mail is the sending of a message (mail) from one computer user to another computer user. The ability to leave a message for another user eliminates "telephone tag." The recipient's computer stores the message until he or she logs in and reads it.

With the advent of computer networks, mail can be sent over networks to a user on another computer.

The BNLDAG VAX is directly connected to 3 of the 4 major world-wide networks (TCP-IP network, Bitnet, DECnet). Mail can be sent to any user on any node in the 3 networks using the standard VAX mail program, MAIL.

Mail can be sent to the remaining fourth world-wide network (UUCP) and numerous minor world-wide networks through a series of intervening computer nodes (gateways). This is done transparently by another special mail program, GMAIL.

\section{$2.0 \mathrm{VAX} / \mathrm{VMS}$ MAIL}

MAIL is Digital Equipment Corporation's official mail program for VAXs. MAIL supports mailing addresses to a user on a:

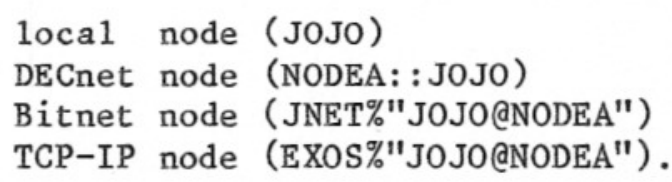

[Note: Many examples in this document use JOJO as user name and NODEA as node name.] 


\subsection{MAIL Command}

By typing in the MAIL command you are then prompted for a11 necessary information. For example: sending a file, LETTER.TXT.

\section{\$MAIL}

MAIL>SEND LETTER.TXT

TO: NODEA : : JOJO

Subj: A word to the wise Mai1>

If you do not specify a file with the SEND subcommand, you are prompted for the message text. For example:

\$MAIL

MAIL $>$ SEND

To: NODEA : : JOJO

Subj: A word to the wise

Enter your message below. Press CTRL/Z when complete.

Keep the mail coming

Truly yours,

DM

$\uparrow Z$

MAIL>

\subsection{GMAIL}

GMAIL (Gateway MAIL) is a utility, implemented by a DCL command file, designed primarily to support the sending of mail messages to nodes on networks other than those directly supported by VMS MAIL. The user interface for GMAIL is patterned closely after the sending functions of VMS MAIL. GMAIL supports a mix of "foreign network" addresses together with addresses which can be handled by VMS MAIL. GMAIL invokes VMS MAIL to deal with those addresses which are VMS MAIL addresses. Hence, GMAIL handles a super-set of MAIL addresses.

The address syntax that GMAIL supports for "foreign-network" addresses is most often in the form "user@host.domain", for instance, "USERX@NODEA.ARPA". Such mail is handled by combining your letter with a suitable header, and sending it to a "gateway" node, from where it is forwarded to its ultimate destination.

\subsection{GMAIL Command}

To send mail with GMAIL, is the same as with VMS MAIL, except you start with the GMAIL command. For example: 
\$GMAIL

gMAIL>SEND LETTER.TXT

gTO: NODEA: : JOJO

Subj: A word to the wise

MAIL>

\subsection{MAIL OR GMAIL}

Try to use MAIL first. It is faster and fully supported by Digital Equipment. New features are always being added. Use MAIL for the three major networks. It can handle: DECnet, Bitnet and TCP-IP networks.

GMAIL is much slower and is not supported by Digital Equipment. Its future is uncertain. Use GMAIL for things MAIL cannot handle: for the major network:UUCP, all minor world-wide networks and for mailing addresses that are undecipherable.

\subsection{Mailing Instructions}

First of all, you need the recipient's mailing address. If you don't have it, create it. Second, by scrutinizing the mailing address, determine whether to use MAIL or GMAIL programs. Third, run the selected mail program.

\subsection{Mailing Address Creation}

To create a mailing address, you must know the network name, node name and user name. Assume node name NODEA and user name JoJo. In the following table, use the network name to find the mailing address format.

\section{Network \\ DECnet \\ Bitnet \\ TCP-IP \\ UUCP}

\section{Mailing address to use}

NODEA : : JOJO

JNET\%"JOJO@NODEA"

EXOS\%"JOJO@NODEA"

JOJO@NODEA. UUCP

Now if the network is not one of the four major international networks, GMAIL on-1ine help may find you a gateway to that network. The on-line help will show you how to create the proper mailing address that will transparently get your mail through one or more gateways.

\$GMAIL gMAIL $>$ HELP GATEWAYS...

\subsection{Sending Mail}

Once you have the mailing address, your last decision is whether to use VMS MAIL or GMAIL. It is always safe to use GMAIL every place VMS MAIL is used. 
Continuing with using node name NODEA and user name JOJO, use the address type in the following table to determine whether to use MAIL or GMAIL. Some addresses may have domain names (fields separated by '.'s) as well as node and user names; we wil1 use '.DOM1', '.DOM2', etc. to represent domains.

\section{Address Type}

NODEA : : JOJO

JNET\%"JOJO@NODEA"

EXOS\%"JOJO@NODEA"

EXOS\%"JOJO@NODEA.DOM1"

EXOS\%"JOJO@NODEA. DOM1.DOM2"

EXOS\%"JOJO@NODEA. DOM1. DOM2. DOM3"

JOJO@NODEA. UUCP

JOJO@NODEA. DOM1

JOJO@NODEA. DOM1 . DOM2. DOM3

Any other address type

\section{Program to use}

MAIL

MAIL

MAIL

MAIL

MAIL

MAIL

GMAIL

GMAIL

GMAIL

GMAIL

\subsection{Examples} either

According to the previous section, to send mail you must be given
a) names of network, node and user, or
b) complete mailing address.

The examples are sectioned according to these two possibilities. Assume the message in all cases is a file LETTER.TXT.

\subsection{Given name of network, node, user}

Here we use section 5.1 to create the address and 5.2 to determine whether to use MAIL or GMAIL.

6.1.1 Given network:DECnet, node:BNLHEP, user:OPR

\$MAIL

>SEND LETTER.TXT

To: BNLHEP: :OPR

6.1.2 Given network:Bitnet, node:YALEVM, user:FOO

\$MAIL

>SEND LETTER.TXT

To: JNET\%:FOO@YLEVM"

6.1.3 Given network:UUCP, node:UCBJADE, user:JACK

The UUCP network can be handled only by GMAIL. 


\author{
\$GMAIL \\ >SEND LETTER.TXT \\ gTo: JACK@UCGJADE. UUCP
}

6.1.4 Given network: TCP-IP network, node:LLL-ICDC, user:OBER

\$MAIL

>SEND LETTER.TXT

To: EXOS\%"OBER@LLL-ICDC"

6.1.5 Given network:Hebrew University Loca1 Area network,

Israel, node:JAF, user:LOUIE

Here we have to search GMAIL's on-line help on gateways to find this network.

\$GMAIL

>HELP GATEWAYS...

We find the network and use the example to create our address :

\$GMAIL

>SEND LETTER.TXT

gTo: LOUIE@JAF. HUJI.AC.IL

\title{
6.2 Given complete mailing address
}

Here we only use section 5.2 to determine whether MAIL or GMAIL is to be used. The given mailing address is used as is.

6.2.1 Given address:

EDU\%"TOM\%NODEA.BITNET@WISCVM.EDU"

Sure looks like something only GMAIL can handle.

\$GMAIL

>SEND LETTER.TXT

gTO: EDU\%"TOM\%NODEA.BITNET@WISCVM.EDU"

6.2.2 Given address

EXOS\%"SUN! NEWS@SEISMO.CSS.GOV"

This fits the fifth item in section 5.2 table, so we use MAIL.

\$MAIL

>SEND LETTER.TXT

To: EXOS\%"SUN!NEWS@SEISMO.CSS.GOV" 
6.2.3 Given address

SYMGR\%UK.AC. KCL. PH. IPG@AC.UK

\$GMAIL

>SEND LETTER.TXT

gTo: SYSMGR\%UK.AC.KCL.PH. IPG@AC.UK

6.2.4 Given address

NET\%"GREGG\%NEMO.MATH. OKSTATE.EDU@RELAY.CS.NET"

\$GMAIL

>SEND LETTER.TXT

gTo: NET\%"GREGG\%NEMO.MATH.OKSTATE, EDU@RELAY.CS.NET"

\subsection{Foreign Address Validation}

GMAIL command, CHKADDRESS, will test the validity of a foreign mailing address without sending a message. For example:

\$GMAIL

GMAIL>CHKADDRESS USER\%TAMVXOCN.BITNET@WISCVM.WISC.EDU

\subsection{References}

8.1 MAIL
a) EP\&S Technical Note 124 -- VAX/VMS MAIL
b) VAX/VMS MAIL Utility Reference Manua1
c) On-line information
\$HELP MAIL
To get a hard copy of the entire help file do \$HELP/OUTPUT=MAIL. LIS MAIL... \$PRINT MAIL.LIS/DELETE

8.2 GMAIL

a) Informational file on BNLDAG
BNL \$MANUAL: GMAIL. MAN

b) On-1ine information

To obtain information about individual commands or topics, enter HELP followed by the command or topic name. gMAIL> HELP [topic [subtopic...]]

A11 GMAIL commands gMAIL> HELP *... 
If this is your first introduction to GMAIL, then topic "Getting started" is a good place to begin. Note that you can output this HELP file (or a part of it) to a printable file by using the following sequence of commands:

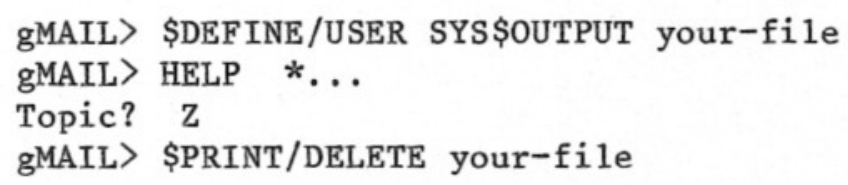

c) To contact the creator and maintainer of GMAIL see:

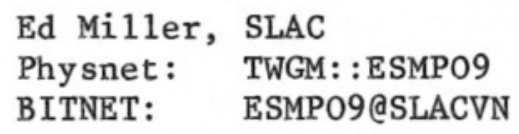

\subsection{Networks in General}

a) EP\&S Technical Note 非23: BNLDAG VAX Networks

b) "Notable Computer Networks", Communications of ACM, October 1986, vol. 29, no. 10, pp 932-970. 